\title{
In reply: Confirmation of tracheal intubation time in adults
}

\author{
Zehra Ipek Arslan ${ }^{1}$
}

Received: 13 January 2016 / Accepted: 18 January 2016 / Published online: 3 February 2016

(C) Japanese Society of Anesthesiologists 2016

Keywords Face-to-face $\cdot$ Airtraq $\cdot$ Glidescope $\cdot$ Fastrach . Adult

To the Editor:

We sincerely thank Dr. Bailong and colleagues for their interest and comments on our manuscript [1]. Our study was designed to simulate a face-to-face intubation in a prehospital area (with no chance for confirmation by capnography). I do not agree with Dr. Bailong et al. that we must always see the vocal cords perfectly to record the endotracheal intubation time. In the Airtraq group we had a patient who had a Cormack-Lehane grade III; only a little part of the glottis was visible, such that you could imagine where you were intubating. It should be graded as CormackLehane II not III. In addition, Amathieu and colleagues investigated face-to-face intubation on an adult manikin and described an intubation time that was consistent with that reported in our study. Similarly, they only visualized the glottis perfectly in $81 \%$ of the Glidescope group and $94 \%$ of the Airtraq group [2]. We propose that it would be more suitable to define the intubation time as the time elapsed from the device entering the oral cavity until the confirmation of successful ventilation using a self-inflating bag connected to the tracheal tube, as previously described by Grosomanidis et al. [3].

\section{Compliance with ethical standards}

Conflict of interest None.

\section{References}

1. Arslan ZI, Alparslan V, Ozdal P, Toker K, Solak M. Face-toface tracheal intubation in adult patients: a comparison of the Airtraq $^{\mathrm{TM}}$, Glidescope ${ }^{\mathrm{TM}}$ and Fastrach ${ }^{\mathrm{TM}}$ devices. J Anesth. 2015;29:893-8.

2. Amathieu R, Sudrial J, Abdi W, Luis D, Hahouache H, Combes X, Dhonneur G. Simulating face-to-face tracheal intubation of a trapped patient: a randomized comparison of the LMA Fas$\operatorname{trach}^{\mathrm{TM}}$, the Glidescope ${ }^{\mathrm{TM}}$ and the Airtraq ${ }^{\mathrm{TM}}$ laryngoscope. Br J Anaesth. 2012;108:140-5.

3. Grosomanidis V, Amaniti E, Pourzitaki Ch, Fyntanidou V, Mouratidis K, Vasilakos D. Comparison between intubation through ILMA and Airtraq, in different non-conventional patient positions: a manikin study. Emerg Med J. 2012;29:32-6.

This comment refers to the article available at doi:10.1007/ s00540-015-2103-z.

Zehra Ipek Arslan

zehraipek48@gmail.com

1 Anesthesiology and Reanimation, Kocaeli University Medical Faculty, Umuttepe, Kocaeli, Turkey 